\title{
Effect of Neurexan on the pattern of EEG frequencies in rats
}

Wilfried Dimpfel ${ }^{1}$, Kerstin Roeska ${ }^{2^{*}}$ and Bernd Seilheimer ${ }^{2}$

\begin{abstract}
Background: Various medications of natural origin have effectively treated stress-related disorders, such as sleep disturbances and agitated conditions. The efficacy of Neurexan, a multicomponent, low-dose medication, has been demonstrated in observational studies, but its exact mechanism of action has not been determined.

Methods: To characterize the effects of Neurexan on the central nervous system, we analyzed the spectral frequencies of field potentials in four rat brain areas after a single oral administration of Neurexan. Different doses of Neurexan were tested within a crossover design, and effects were compared with vehicle control.

Results: Significant effects were observed with 0.5 tablets of Neurexan, predominantly on $\delta$ - and $\theta$-waves in the frontal cortex and reticular formation $(P<0.01)$. In the reticular formation, significant changes of $\delta$ - and $\theta$-waves occurred as early as during the first hour after administration. The time course revealed a significant and longer-lasting increase of $\delta$ - and $\theta$-waves in the frontal cortex and reticular formation, whereas other spectral frequencies were only transiently affected in the frontal cortex, reticular formation, and striatum.

Conclusion: In conclusion, this study demonstrated that the low-dose medication Neurexan influences central nervous system activity in rats. The resulting electroencephalographic profile of Neurexan shows several similarities with those of other calming agents, such as Valeriana and Passiflora, suggesting a potential benefit of Neurexan for patients with stress-related disorders. Moreover, this report demonstrates that electroencephalographic signatures are also valid biomarkers for the assessment of low-dose medications, such as Neurexan.
\end{abstract}

Keywords: Central nervous system, Stress-related disorders, Multitargeted, Multicomponent, Brain waves, Electroencephalography

\section{Background}

Stress-related disorders, such as mild anxiety, nervousness, and insomnia, are widespread among the population. For example, the prevalence of anxiety disorders and insomnia reaches $16.6 \%$ and $26 \%$, respectively $[1,2]$. Currently used medications include benzodiazepines and serotonin-specific reuptake inhibitors. However, these medications can be accompanied by considerable adverse effects, such as cognitive impairment and dependency [3-5]. For the treatment of stress-related disorders, self-medication is often practiced, and there is a strong association between stress and alcohol consumption [6],

\footnotetext{
* Correspondence: kerstin.roeska@heel.com

${ }^{2}$ Biologische Heilmittel Heel GmbH, Dr.-Reckeweg-Str. 2-4, Baden Baden 76532, Germany

Full list of author information is available at the end of the article
}

leading to the known potential consequences for physical and psychological health.

Clinical studies have documented that complementary and alternative medicine effectively treats stress-related disorders, such as sleep disturbance and anxiety-related conditions, without serious adverse effects $[7,8]$. For example, Neurexan is a multicomponent drug constituted of highly diluted natural, mainly plant, extracts. It is recommended to treat mild sleep disturbances and agitated conditions [9].

The effectiveness of the single components of Neurexan (passiflora incarnata [Passiflora], avena sativa, coffea arabica, and zincum isovalerianicum) has been demonstrated in human and animal studies. Three randomized controlled trials demonstrated the anxiolytic efficacy of Passiflora as monotherapy $[10,11]$ and as part of an herbal combination [12]. Animal studies demonstrated the sedative effects of avena sativa [13] and

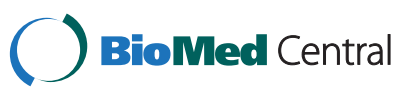


increased sleep intensity by diluted preparations of coffea cruda [14]. In a retrospective analysis, a potential beneficial effect of zincum isovalerianicum in patients with restless legs syndrome could be observed [15].

Although these components are less concentrated in Neurexan than in the reference drugs tested in the previously mentioned studies, Neurexan is effective for the treatment of moderate insomnia and nervousness. In two observational studies, Neurexan was demonstrated as a well-tolerated alternative to conventional valeriana officinalis (Valeriana)-based therapies for the treatment of moderate insomnia and nervousness [16,17].

As a multicomponent medication, Neurexan presumably acts on different targets, and the resulting net effect on the central nervous system has not been characterized. During the past decade, electroencephalography (EEG) has provided surrogate measures of drug efficacy of psychoactive drugs. The EEG signature obtained from the spectra of oscillation frequencies may differ between baseline and experimental conditions. Therefore, an EEG signature might be seen as a biomarker [18].

Biomarkers are increasingly used to both predict the clinical response to treatment and characterize the mechanism of action [19]. For instance, changes of EEG signatures observed after administration of experimental compounds can be assigned to the interference of drugs with certain neurotransmitter systems, such as the cholinergic, dopaminergic, and noradrenergic systems [20-23]. Moreover, different drug categories, such as antidepressive, anticonvulsive, analgesic, neuroleptic, stimulatory, narcotic, sedative, and hallucinogenic drugs, result in a reproducible and disease-specific EEG signature. Therefore, unknown compounds could be classified into distinct drug categories by discriminant analysis of EEG data [24]. More important, the conservation of brain structure and neurobiological features across mammalian species allows the translatability of results [18].

In this report, we asked if the multicomponent, lowdose medication Neurexan induces an EEG signature that explains its calming effects. To answer this question, we characterized the effect of different doses of Neurexan on the EEG of four rat brain areas during 5hour experiments.

\section{Methods}

Drugs

Neurexan (Heel GmbH, Baden-Baden, Germany) is an over-the-counter medication constituted of highly diluted ingredients. One tablet consists of $0.6 \mathrm{mg}$ passiflora incarnata D2, $0.6 \mathrm{mg}$ avena sativa D2, $0.6 \mathrm{mg}$ coffea arabica $\mathrm{D} 12,0.6 \mathrm{mg}$ zincum isovalerianicum $\mathrm{D} 4,1.5 \mathrm{mg}$ magnesium stearate, and $300 \mathrm{mg}$ lactose-monohydrate (D indicates dilution). All components are prepared according to the European Pharmacopoeia [25].
Neurexan is recommended for the treatment of mild sleep disturbances and agitated conditions [9]. In animal experiments, Neurexan was dissolved in $0.9 \% \mathrm{NaCl}$ ( $1 \mathrm{~mL} / \mathrm{kg}$ body weight). The applied doses of Neurexan $(0.25,0.50$, or 1 tablet per animal) correspond to the 6to 12-fold human equivalent dosage [26]. Neurexan or vehicle controls $(1 \mathrm{~mL} / \mathrm{kg} 0.9 \% \mathrm{NaCl})$ were orally administered as a single dose. Other drugs used as comparators in discriminant analyses were described earlier [24].

\section{Animals}

Eight 8-month-old Fisher 344 rats (Charles River Laboratories, Sulzfeld, Germany) were kept at the preclinical study center (NeuroCode AG, Wetzlar, Germany) in sterile filter-top cages on a reversed daynight cycle and provided with food and water ad libitum. Animal procedures were performed according to German health guidelines and animal protection laws and were approved by the Regional Commission Gießen (GI 21/4-Nr.66-2009, Regierungspräsidium Gießen, Schanzenfeldstraße 8, 35578 Wetzlar). For surgery, animals were anesthetized with an intramuscular injection of $10 \%$ ketamine hydrochloride $(1 \mathrm{~mL} / \mathrm{kg})$. Four concentric bipolar steel electrodes were then implanted in the left hemisphere ( $3 \mathrm{~mm}$ lateral) by stereotactic surgery. The anterior coordinates were 12.2, 5.7, 9.7, and $3.7 \mathrm{~mm}$ for the frontal cortex, hippocampus, striatum, and reticular formation, respectively [27]. A plate carrying four bipolar SNF100 neurological electrodes (Rhodes Medical Instruments Inc, Summerland, CA), a 5-pin plug, and a transmitter $(26 \times 12 \times 6 \mathrm{~mm} ; 5.2 \mathrm{~g})$ was fixed on the skull by three steel screws and dental cement.

\section{EEG recording}

For the recording of EEG signals, cages were placed in a copper-shielded room. As described earlier, signals were transmitted by a wireless radio-telemetric system (Rhema Labortechnik, Hofheim, Germany) and processed to give power spectra of $0.25-\mathrm{Hz}$ resolution [28]. After automatic artifact rejection, signals were collected in 4-second units and fast Fourier transformed using a Hanning window. Sampling frequency was $512 \mathrm{~Hz}$. Four values were averaged to give a final sampling frequency of $128 \mathrm{~Hz}$, well above the Nyquist frequency. The resulting electrical power spectra were divided into $\delta$-waves (0.8-4.5 Hz), $\theta$-waves $(4.75-6.75 \mathrm{~Hz}), \alpha 1$-waves $(7.00$ $9.50 \mathrm{~Hz}), \alpha 2$-waves $(9.75-12.50 \mathrm{~Hz}), \beta 1$-waves $(12.75$ $18.50 \mathrm{~Hz})$, and $\beta 2$-waves $(18.75-35.00 \mathrm{~Hz})$. Spectra were averaged every 3 minutes. For further analysis, periods of 60 minutes were averaged. To exclude circadian effects, all measurements were performed at the same time. During recording, rats were moving freely but could not eat to avoid artifacts. 


\section{Study design}

The study began 2 weeks after surgery. Animals were assigned to receive different doses of Neurexan or vehicle control in a crossover design. All eight animals were exposed to one dose per experiment and then received a different dose after a 1-week washout period. In each experiment, a single dose of Neurexan or vehicle control was administered orally after a predrug baseline recording for 45 minutes. Then, after a 5-minute interval for recovery, EEG signals were recorded for 5 hours.

\section{Statistics}

The EEG signals (in $\mu \mathrm{V}^{2}$ ) were documented in hourly intervals as percentage of baseline signals. Each of the six frequency bands within each brain region was measured, and the data of eight animals were summarized as mean \pm SEM. The differences of frequency band changes between Neurexan and vehicle-treated rats were tested for significance using the Wilcoxon Mann-Whitney $U$ test. $P<0.01$ was considered significant.

\section{Results}

The dose-response relationship between Neurexan and EEG signatures revealed a predominant effect on $\delta_{-}, \theta_{-}$, and $\alpha 2$-waves in the frontal cortex and reticular formation (Figure 1). Changes of spectral frequencies were analyzed between 185 and 245 minutes after oral administration of a single dose of Neurexan. Although changes of spectral frequencies were observed at each dosage $(0.25,0.5$, or 1 tablet), most significant changes were found with 0.5 tablets of Neurexan. At this concentration, $\delta$-, $\theta$-, and $\alpha 2$-waves were significantly changed in the frontal cortex when compared with vehicle control (Figure 1A). Moreover, $\delta$-, $\theta-$, and $\alpha 2$-waves and, in addition, $\alpha 1$ - and $\beta 1$-waves were significantly altered in the reticular formation (Figure 1D). In the hippocampus, only $\delta$-waves were significantly affected by treatment with 1 tablet of Neurexan (Figure 1B). Between 185 and 245 minutes, no significant change of spectral frequencies could be observed in the striatum (Figure 1C).

Over time, 0.5 tablets of Neurexan significantly changed most spectral frequencies in the frontal cortex, reticular formation, and striatum when compared with vehicle control. Effects were predominantly observed on $\delta$ - and $\theta$-waves (Figure 2). In the frontal cortex, $\delta$ - and $\theta$-waves persistently and significantly increased during the third to fourth hour and during the fourth to fifth hour after administration, respectively (Figure $2 \mathrm{~A}$ ). In the reticular formation, $\delta$ - and $\theta$-waves significantly increased during the third to fifth hour and, in addition, during the first hour after administration (Figure 2D). Other spectral frequencies were only transiently affected by Neurexan. In the frontal cortex and reticular formation, $\alpha 1-, \alpha 2-$, and $\beta 1$-waves were significantly increased at single experimental intervals. In the striatum, changes of $\theta$-waves reached significance at two experimental intervals (third and fifth hours, Figure 2C), whereas no significant changes were observed in the hippocampus at this dosage (Figure 2B).

Taken together, Figures 1 and 2 demonstrate that even a single dose of Neurexan significantly modulated the EEG signature of several brain areas when compared with vehicle control. The EEG changes predominantly affected $\delta_{-}, \theta_{-}$, and, to a minor extent, $\alpha 2$-waves in the frontal cortex and reticular formation.

\section{Discussion}

Herein, we demonstrate that the low-dose medication Neurexan induces significant changes of rat EEG signatures. Neurexan-induced changes predominantly affect $\delta$ - and $\theta$-waves in the frontal cortex and reticular formation, supporting the fact that Neurexan generally exhibits calming effects.

The rat EEG signature was significantly altered after a single oral administration of Neurexan when compared with vehicle control, thus characterizing Neurexan as psychoactive. Changes were observed in the reticular formation as early as during the first hour after administration. This immediate effect differentiates Neurexan from other plant-derived drugs against stress-related disorders that are effective as early as 3 hours after administration [29]. At later time points, EEG signatures of the frontal cortex and striatum, but not the hippocampus, were also affected by Neurexan.

After having established the principal evidence of dose- and time-dependent effects of Neurexan on the central nervous system, we found a predominant increase of $\delta$ - and $\theta$-waves, supporting the calming effect of Neurexan in general. Earlier publications have demonstrated that pharmacological interference with neurotransmitter systems results in changes of distinct brain waves. Accordingly, changes of $\delta$-waves correspond to interference with the cholinergic system [20]. The fact that enhancing cholinergic transmission in the reticular formation increases rapid eye movement sleep in several species [30-32] might, therefore, contribute to an explanation of the beneficial effects of Neurexan on sleep disturbance [16]. According to previous studies $[21,33]$, Neurexan-induced changes of $\alpha 2$-waves can be interpreted as inactivation of the dopaminergic system, whereas increases of $\theta$-waves could be related to interference with the norepinephrine $\alpha 2$ receptor, leading to sedation [22].

The effects on EEG signatures in rats have been demonstrated for several different synthetic and plantderived psychoactive substances, and, more important, the same method of EEG recording was used in these studies [20,24,28]. We were, therefore, able to 




descriptively compare the net effects of Neurexan on six frequency bands in four rat brain areas with those of other substances. It might not be scientifically adequate to draw direct conclusions from these comparisons, but several similarities between Neurexan and Valeriana or Passiflora could be found (data not shown).

Both Valeriana and Passiflora are present in Neurexan, although at a far smaller concentration. Several clinical trials have demonstrated that Valeriana effectively treats insomnia mostly by reducing sleep latency and improving sleep quality. In two double-blind and placebocontrolled studies, single doses between 400 and $900 \mathrm{mg}$ significantly improved sleep latency and sleep quality when compared with placebo $[34,35]$. In two randomized, double-blind studies, the effects of Valeriana $(600 \mathrm{mg} / \mathrm{d})$ on insomnia were comparable to those of Oxazepam [36,37]. Interestingly, a high dosage of Valeriana (1500 mg Valeriana in combination with $360 \mathrm{mg}$ hops) particularly increased $\delta$-waves in human subjects [38]. However, the concentration of Valeriana in Neurexan is far lower $(0.6 \mathrm{mg}$ valerianate of zinc D4 per tablet), but Neurexan has been as effective as Valerianabased therapies for the treatment of mild to moderate insomnia [16]. Either highly diluted valerianate of zinc might be as effective as high-dose Valeriana or, more probably, the combination of valerian ate of zinc with other components of Neurexan synergistically mediates calming effects.

The second comparator drug generating a similar EEG signature such as Neurexan, Passiflora, exerts anxiolytic effects in mice $[39,40]$ and humans [10-12]. In a doubleblind, placebo-controlled trial, Passiflora has been as effective as benzodiazepine in eliminating anxiety symptoms [10]. Doses of $10 \mathrm{mg} / \mathrm{kg}$ body weight were effective in mice [39]. In our experiments, the reference drug Passiflora was applied at a dose of $100 \mathrm{mg} / \mathrm{kg}$ and predominantly increased $\theta$-activity in the frontal cortex and striatum (data not shown). Likewise, $1200 \mathrm{mg}$ of 


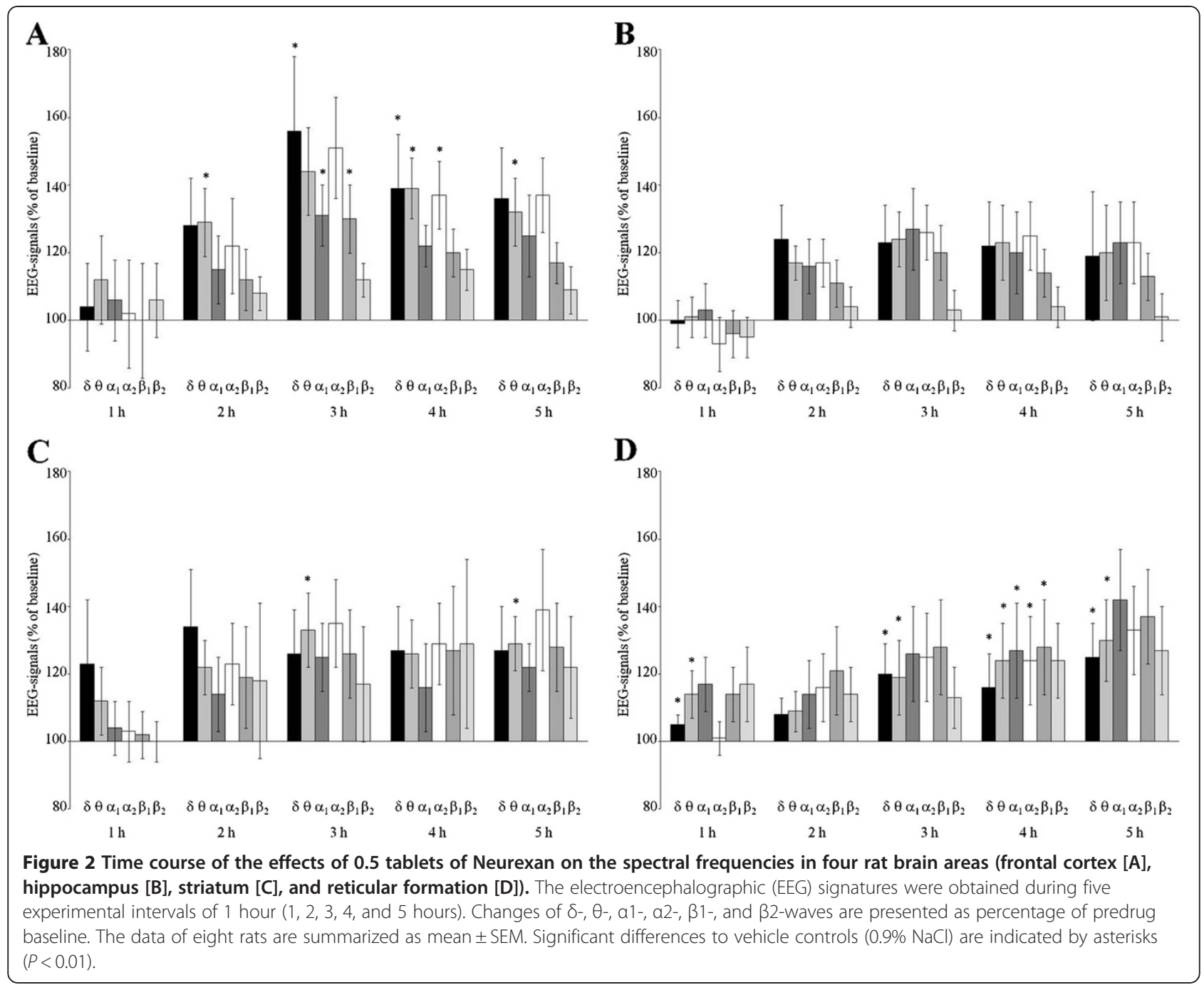

Passiflora extract strongly increased $\theta$-waves and slightly increased $\delta$-waves in patients with sleep disorders [41]. Concerning this influence on EEG activity, Neurexan containing low-dose Passiflora seems to be comparably effective as the high-dose comparator drug.

We recognize two major limitations of our study. First, the number of animals in our study was relatively small, but the sample size was sufficient to detect significant effects $(P<0.01)$ on the EEG signature in rats. Second, our results are rather descriptive and need to be correlated with the effects of Neurexan on human subjects, even if the translatability of results across mammalian species might be widely accepted [18]. However, one objective of our study was to demonstrate an effect of this low-dose and multicomponent medication on the central nervous system, providing a starting point for further research. Correlation with the effectiveness of Neurexan on moderate insomnia and nervousness has already been provided by two observational studies $[16,17]$. Moreover, a double-blind, placebo-controlled trial is conducted to evaluate the psychophysiological effects of Neurexan on human subjects in more detail.

\section{Conclusion}

In summary, the current study demonstrated that the multicomponent, low-dose medication, Neurexan, influences neuronal activity in particular brain areas, thereby suggesting that the drug has calming effects. The similarity of Neurexan with other medications with known calming effects suggests that the combination of the lower concentrated components of Neurexan exerts an additive and synergistic effect on neuroactivity. It can be speculated that Neurexan has beneficial effects for patients with stress-related disorders. Moreover, this report demonstrates that EEG signatures are valid biomarkers for the psychoactivity of multicomponent, low-dose medications, such as Neurexan. The outcome gives guidance for further scientific investigations of that drug, to identify the working mechanism and its efficacy in more detail. 


\section{Abbreviations}

EEG: Electroencephalography; CNS: Central nervous system; NaCl: Natrium chloride; D: Dilution; SEM: Standard error of the mean; REM: Rapid eye movement.

\section{Competing interests}

Research by W. Dimpfel (NeuroCode AG) was performed on behalf of Biologische Heilmittel Heel $\mathrm{GmbH}$ that also provided financial support for editorial assistance and scientific writing services. K. Roeska and B. Seilheimer are employees of Biologische Heilmittel Heel $\mathrm{GmbH}$.

\section{Authors' contributions}

WD was responsible for the performance of the experiments. KR made substantial contributions to the interpretation of the data and was involved in drafting the manuscript. BS was involved in writing the manuscript and approved the final version. All authors read and approved the final manuscript.

\section{Acknowledgments}

We thank Dr. Stefan Lang for his medical editorial assistance and scientific writing services. We acknowledge Mrs. Leonie Schombert for performing the experiments and statistical evaluation of data.

\section{Author details}

'Justus-Liebig-University Giessen, NeuroCode AG, Sportparkstrasse 9, Wetzla 35578, Germany. Biologische Heilmittel Heel GmbH, Dr.-Reckeweg-Str. 2-4, Baden Baden 76532, Germany.

Received: 9 February 2012 Accepted: 12 August 2012

Published: 16 August 2012

\section{References}

1. Somers JM, Goldner EM, Waraich P, Hsu L: Prevalence and incidence studies of anxiety disorders: a systematic review of the literature. Can $J$ Psychiatry 2006, 51:100-113.

2. Strine TW, Chapman DP: Associations of frequent sleep insufficiency with health-related quality of life and health behaviors. Sleep Med 2005, 6:23-27.

3. Rosenberg RP: Sleep maintenance insomnia: strengths and weaknesses of current pharmacologic therapies. Ann Clin Psychiatry 2006, 18:49-56.

4. Cascade E, Kalali AH, Kennedy SH: Real-world data on SSRI antidepressant side effects. Psychiatry (Edgmont) 2009, 6:16-18.

5. O'brien CP: Benzodiazepine use, abuse, and dependence. J Clin Psychiatry 2005, 66(Suppl 2):28-33.

6. Dawson DA, Grant BF, Ruan WJ: The association between stress and drinking: modifying effects of gender and vulnerability. Alcohol Alcohol 2005, 40:453-460.

7. Lakhan SE, Vieira KF: Nutritional and herbal supplements for anxiety and anxiety-related disorders: systematic review. Nutr J 2010, 9:42.

8. Meeks TW, Wetherell JL, Irwin MR, Redwine LS, Jeste DV: Complementary and alternative treatments for late-life depression, anxiety, and sleep disturbance: a review of randomized controlled trials. J Clin Psychiatry 2007, 68:1461-1471.

9. Heel GmbH: Neurexan Package Insert. Baden-Baden,Germany: Heel GmbH; 2004.

10. Akhondzadeh S, Naghavi HR, Vazirian M, Shayeganpour A, Rashidi H, Khani M: Passionflower in the treatment of generalized anxiety: a pilot doubleblind randomized controlled trial with Oxazepam. J Clin Pharm Ther 2001, 26:363-367.

11. Movafegh A, Alizadeh R, Hajimohamadi F, Esfehani F, Nejatfar M Preoperative oral Passiflora incarnata reduces anxiety in ambulatory surgery patients: a double-blind, placebo-controlled study. Anesth Analg 2008, 106:1728-1732.

12. Bourin M, Bougerol T, Guitton B, Broutin E: A combination of plant extracts in the treatment of outpatients with adjustment disorder with anxious mood: controlled study versus placebo. Fundam Clin Pharmacol 1997, 11:127-132.

13. Connor J, Connor T, Marshall PB, Reid A, Turnbull MJ: The pharmacology of Avena sativa. J Pharm Pharmacol 1975, 27:92-98.

14. Ruiz-Vega G, Perez-Ordaz L, Cortes-Galvan L, Juarez G: A kinetic approach to caffeine-Coffea cruda interaction. Homeopathy 2003, 92:19-29.
15. Kröz M, Anders S, Brauer D, Zerm R, Schad F, Girke M: Valerianate of Zinc in Restless Legs Syndrome: A Retrospective Analysis [in German]. Erfahrungsheilkunde 2009, 58:121-129.

16. Waldschutz R, Klein P: The homeopathic preparation Neurexan vs. valerian for the treatment of insomnia: an observational study. ScientificWorldJournal 2008, 8:411-420.

17. Hubner R, Klein P, van HR: Effectiveness of the homeopathic preparation Neurexan compared with that of commonly used valerian-based preparations for the treatment of nervousness/restlessness - an observational study. ScientificWorldJournal 2009, 9:733-745.

18. Leiser SC, Dunlop J, Bowlby MR, Devilbiss DM: Aligning strategies for using EEG as a surrogate biomarker: a review of preclinical and clinical research. Biochem Pharmacol 2011, 81:1408-1421.

19. Kuhlmann J, Wensing G: The applications of biomarkers in early clinical drug development to improve decision-making processes. Curr Clin Pharmacol 2006, 1:185-191.

20. Dimpfel W: Pharmacological modulation of cholinergic brain activity and its reflection in special EEG frequency ranges from various brain areas in the freely moving rat (Tele-Stereo-EEG). Eur Neuropsychopharmacol 2005, 15:673-682.

21. Dimpfel W, Spuler M, Koch R, Schatton W: Radioelectroencephalographic comparison of memantine with receptor-specific drugs acting on dopaminergic transmission in freely moving rats. Neuropsychobiology 1987, 18:212-218

22. Dimpfel W, Schober F: Norepinephrine, EEG theta waves and sedation in the rat. Brain Pharmacology 2001, 1:89-97.

23. Sebban C, Zhang XQ, Tesolin-Decros B, Millan MJ, Spedding M: Changes in EEG spectral power in the prefrontal cortex of conscious rats elicited by drugs interacting with dopaminergic and noradrenergic transmission. $\mathrm{Br}$ J Pharmacol 1999, 128:1045-1054.

24. Dimpfel W: Preclinical data base of pharmaco-specific rat EEG fingerprints (tele-stereo-EEG). Eur J Med Res 2003, 8:199-207.

25. Council of Europe, European Pharmacopoeia Commission, European Directorate for the Quality of Medicines \& Healthcare: European Pharmacopoeia. Strasbourg: Council of Europe; 2010.

26. Reagan-Shaw $S$, Nihal $M$, Ahmad N: Dose translation from animal to human studies revisited. FASEB J 2008, 22:659-661.

27. Paxinos $G$, Watson C: The rat brain in stereotactic coordinates. New York: Academic Press; 1982.

28. Dimpfel W, Spuler M, Nickel B: Radioelectroencephalography (Tele-StereoEEG) in the rat as a pharmacological model to differentiate the central action of flupirtine from that of opiates, diazepam and phenobarbital. Neuropsychobiology 1986, 16:163-168.

29. Dimpfel W, Koch K, Weiss G: Early effect of NEURAPAS(R) balance on current source density (CSD) of human EEG. BMC Psychiatry 2011, 11:123

30. Baghdoyan HA, Monaco AP, Rodrigo-Angulo ML, Assens F, McCarley RW, Hobson JA: Microinjection of neostigmine into the pontine reticular formation of cats enhances desynchronized sleep signs. J Pharmacol Exp Ther 1984, 231:173-180.

31. Bourgin P, Escourrou P, Gaultier C, Adrien J: Induction of rapid eye movement sleep by carbachol infusion into the pontine reticular formation in the rat. Neuroreport 1995, 6:532-536.

32. Shiromani PJ, Fishbein W: Continuous pontine cholinergic microinfusion via mini-pump induces sustained alterations in rapid eye movement (REM) sleep. Pharmacol Biochem Behav 1986, 25:1253-1261.

33. Dimpfel W: Pharmacological modulation of dopaminergic brain activity and its reflection in spectral frequencies of the rat electropharmacogram. Neuropsychobiology 2008, 58:178-186.

34. Leathwood PD, Chauffard F, Heck E, Munoz-Box R: Aqueous extract of valerian root (Valeriana officinalis L.) improves sleep quality in man. Pharmacol Biochem Behav 1982, 17:65-71.

35. Leathwood PD, Chauffard F: Aqueous extract of valerian reduces latency to fall asleep in man. Planta Med 1985, 2:144-148.

36. Dorn M: Efficacy and tolerability of Baldrian versus Oxazepam in nonorganic and non-psychiatric insomniacs: a randomized, double-blind, clinical, comparative study [in German]. Forsch Komplementar med Klass Naturheilkd 2000, 7:79-84.

37. Ziegler G, Ploch M, Miettinen-Baumann A, Collet W: Efficacy and tolerability of valerian extract LI 156 compared with Oxazepam in the treatment of non-organic insomnia-a randomized, double-blind, comparative clinical study. Eur J Med Res 2002, 7:480-486. 
38. Vonderheid-Guth B, Todorova A, Brattström A, Dimpfel W:

Pharmacodynamic effects of valerian and hops extract combination (Ze 91019) on the quantitative-topographical EEG in healthy volunteers. Eur J Med Res 2000, 5:139-144.

39. Dhawan K, Kumar S, Sharma A: Anti-anxiety studies on extracts of Passiflora incarnata Linneaus. J Ethnopharmacol 2001, 78:165-170.

40. Basta M, Chrousos GP, Vela-Bueno A, Vgontzas AN: Chronic insomnia and stress system. Sleep Med Clin 2007, 2:279-291.

41. Schulz H, Jobert M, Hübner WD: The quantitative EEG as a screening instrument to identify sedative effects of single doses of plant extracts in comparison with diazepam. Phytomedicine 1998, 5:449-458.

doi:10.1186/1472-6882-12-126

Cite this article as: Dimpfel et al.: Effect of Neurexan on the pattern of

EEG frequencies in rats. BMC Complementary and Alternative Medicine 2012 12:126.

\section{Submit your next manuscript to BioMed Central and take full advantage of:}

- Convenient online submission

- Thorough peer review

- No space constraints or color figure charges

- Immediate publication on acceptance

- Inclusion in PubMed, CAS, Scopus and Google Scholar

- Research which is freely available for redistribution 